\title{
Convergence on Self-Generated vs. Crowdsourced Ideas in Crisis Response: Comparing Social Exchange Processes and Satisfaction with Process
}

\author{
Isabella Seeber, Alexander \\ Merz, Ronald Maier \\ ${ }^{1}$ University of Innsbruck \\ firstname.lastname@uibk.ac.at
}

\author{
GJ de Vreede \\ University of South Florida \\ gdevreede@usf.edu
}

\author{
Barbara Weber ${ }^{1}$ \\ Technical University of \\ Denmark \\ bweb@dtu.dk
}

\begin{abstract}
Social media allow crowds to generate many ideas to swiftly respond to events like crises, public policy discourse, or online town hall meetings. This allows organizations and governments to harness the innovative power of the crowd. As part of this setting, teams that process crowd ideas must engage in social exchange processes to converge on a few promising ideas. Traditionally, teams work on self-generated ideas. However, in a crowdsourcing scenario, such as public participation in crisis response, teams may have to process crowd-generated ideas. To better understand this new practice, it is important to investigate how converging on crowdsourced ideas affects the social exchange processes of teams and resulting outcomes. We conducted a laboratory experiment in which small teams working in a crisis response setting converged on self-generated or crowdsourced ideas in an emergency response context. Our findings suggest that teams converging on selfgenerated ideas have better social exchange processes in terms of dominance and coordination. We found support that evaluation and coordination positively affect team member satisfaction under both experimental conditions. Implications for research and practice are discussed.
\end{abstract}

\section{Introduction}

Social media (e.g., Twitter, Facebook, Instagram) facilitate civilian-driven grassroots initiatives when governmental crisis response to natural or man-made extreme events fails to become effective. For example, when more than 1.8 million asylum seekers crossed European borders during the peak of the European migration crisis in 2015 [1], effective help needed to be quickly organized. For example, a civilian grassroots initiative set up the website http://refugees.at to collect information through Twitter feeds based on names of highly frequented train stations and action verbs, such as 'need' or 'donate'. This allowed hundreds of civilian volunteers and emergency response teams to disseminate information and coordinate supplies in order to support the transport of several thousand migrants per day through Austria. Similarly, the Facebook page 'Fluthilfe Dresden'1 updated volunteers from and around Dresden via Facebook where help was needed during the severe flooding all over central Europe in 2013.

Governmental crisis response teams could benefit from such initiatives, but only if they were able to harness the innovative ideas generated by the crowd for emergency response. To this end, crisis response teams need to seek high levels of productivity in terms of idea generation, evaluation, and selection [2]. Given the urgency and dynamic environment, decisions must be made swiftly [3, 4]. Yet, past research shows that people perform poorly when they need to select ideas, as they are not able to pick innovative ideas, which are usually characterized as being novel and unique $[5,6]$.

One way to facilitate the idea evaluation and selection phase is to execute a convergence phase immediately following the ideation phase. Idea convergence is a team process in which members reduce the number of ideas to focus on the few they deem worthy of further attention and in which they clarify those ideas to increase shared understanding [7]. During idea convergence, team members engage in social exchanges to arrive at a manageable subset of ideas that can be evaluated in more detail with reasonable effort. Social exchange processes have a significant impact on team performance and are indicative of the quality of teamwork [8,9]. They describe the 'member's perception of his or her willingness to assist other members, to share ideas and feedback and in turn, how readily information, help, and recognition are received from other members' [10, p. 119]. The quality of social exchange processes may

\footnotetext{
${ }^{1}$ https://www.facebook.com/FluthilfeDresden
} 
develop and improve over time with continuous interactions. Social exchanges among team members may concern the coordination of the team's activities or the evaluation of the team's task at hand $[11,12]$.

Social exchange processes are hardly examined in detail [8, 13]. Furthermore, there is limited understanding of how social exchange processes differ when teams interact with ideas that are their own or that originate from an external source. In other words, it is not clear if the quality of social exchange processes is similar when teams converge on selfgenerated ideas or on crowdsourced ideas. Moreover, social exchanges during team processes like idea convergence may be critical determinants of team outcomes. To get a more complete understanding of team dynamics and outcomes, a deeper exploration of a team's social exchanges is required [14].

This study addresses these gaps by investigating social exchange processes in two distinct situations: teams converging on self-generated ideas vs. teams converging on crowdsourced ideas. We posit that teams that self-generate their ideas can trace back the idea to understand how it was generated [5, p. 5] and therefore may develop higher quality social exchange processes than teams that engage in social exchange with crowdsourced ideas. We further investigate to what extent social exchange processes during convergence are associated with the team members' perceptions of satisfaction. Process satisfaction is an important predictor of future adoption and application of team procedures and supporting technology $[15,16]$. Thus, it is not only important for crisis response teams to understand the effectiveness of different idea convergence approaches, but also how the social exchanges inherent in these processes affect perceived satisfaction. Highly effective approaches may still be abandoned or rejected by teams if they feel dissatisfied [17].

The remainder of this paper is structured as follows: The next section provides an overview of the two foundations of our work: social exchange theory and idea convergence. Next, we present our hypotheses and describe the details of our research methods. Then, we present our results and conclude the paper with a discussion of our key findings, their implications, the limitations of our study, and an overview of future research directions.

\section{Background}

\subsection{Social exchange theory}

Blau [18] describes social exchanges as interdependent actions among people. High-quality relationships emerge through a series of such interactions [19] and have been found to positively affect team member's creativity [14], facilitate empowerment [20] or learning [21]. Outcomes of social exchange are a combined result of transactions between two or more interdependent people [8] and comprise, for example, organizational citizenship behavior, commitment, and job satisfaction [22].

Social exchange theory is based on three foundational concepts: (1) resources exchanged, (2) exchange structures, (3) relationships that emerge [8, 12]. Resources can be represented by information, money, good, services, but also love and status and are transferred during social exchange [8]. They are possessions or capabilities of an actor [23]. Consequently, when team members interact during idea convergence, the resources of interaction include, but may not be limited to the ideas that they aim to reduce and clarify. Common structures of social exchanges include productive, reciprocal and negotiated exchanges [12, 23]. Negotiated exchanges describe interdependent transactions among actors that 'engage in a joint decision process in which they seek agreement on the terms of exchange' [23, p. 2], for example bargaining salary or dividing household chores. Reciprocal exchanges describe interdependent transactions among actors that perform 'a beneficial act for another without knowing whether, when, or to what extent the other will reciprocate' [23, p. 3], e.g. an employee who asks a colleague for feedback without expecting anything in return. Only later, that colleague asks the employee for a similar favor. Productive exchange describes a task with 'a single socially produced event or good that occurs only if members perform certain behaviors' [12, p. 336], e.g. co-authors contributing their knowledge or specific talent on a joint paper. The research reported in this paper conceptualizes social exchange among team members as transactions under the productive structure. Emerging relationships are the result of a series of interdependent exchanges [8] and comprise cognitive, behavioral, or affective emergent states and outcomes [24, 25]. A meta-analytical review showed that high quality social exchange relationships among team members positively affect job performance, job satisfaction, and organizational commitment [22].

\subsection{Idea convergence}

Convergence was originally defined as 'to move from a state of having many concepts to a state of having a focus on and understanding of the few worthy of further attention' [7, p. 47]. Subsequent research reconceptualized convergence as a combination of two other patterns that often occur simultaneously in group activities - reduce and clarify. Reduce means, 'to move from having many ideas in the shared set to a focus on 
the few deemed worthy of more attention' and clarify means, 'to move from less to more shared understanding of the meaning of concepts shared by the group' [26, p. 127]. During convergence, a team works on a collection of generated ideas addressing problems and/or solutions [27], reduces and clarifies these ideas in preparation for evaluation [7]. Thus, the goal of a convergence activity is to arrive at a manageable set of unique, on-task and clarified ideas that are on a similar level of abstraction [28]. To this end, teams perform several sub-activities during a convergence phase such as filtering, abstracting, synthesizing, and clarifying [29].

Convergence has been identified as one of the most challenging team processes [29, 30], in terms of cognitive load on team members [31].

\section{Hypotheses development}

Recently, it has been suggested that the source of ideas, for example self-generated or crowdsourced, may have a profound influence on the social exchange processes that occur during idea convergence. Yet, detailed research on this phenomenon is thus far scarce [33].

The sharing of resources in the form of information among team members is central to any social exchange [8]. Information sharing is particularly important for team members working on ill-structured tasks [10], such as idea convergence. During convergence, team members share information to improve shared understanding and determine the fate of brainstormed ideas (i.e. to keep an idea for future consideration or to toss it out). The social exchange process that involves sharing and integrating information to decide on how to process individual ideas is called 'evaluation'.

When teams self-generate their ideas, they are expected to have a sense of familiarity that makes them process and share information more effectively than crowdsourced ideas [33]. Self-generated ideas allow teams to better connect to one's semantic network than crowdsourced ideas [33, 34]. Clarifying self-generated ideas should therefore be more effective since team members can build upon one's own ideas [33]. Girotra and colleagues [5] referred to this as ideas having 'path dependence'. This means that while crowdsourced ideas seem to appear out of nowhere, self-generated ideas may come with information on the path by which they were generated. This is in line with research on egocentric bias [35], suggesting that team members can recall information regarding their own contributions more readily and accurately. Team members' inputs should be more reflected as they may direct more attention towards thinking how to best verbalize their position and argue for their contribution.
Consequently, teams that converge on self-generated ideas may not simply respond to the idea itself, but also to its history [5]. This allows them to exchange information on self-generated ideas more accurately. Team members can inquire about the meaning of ideas, as the idea contributor is among them, and they can discuss how this idea builds on other ideas or why the contribution should be retained. Therefore, we hypothesize that teams working with self-generated ideas will more deeply engage in the evaluation process of social exchange.

H1: Team members converging on self-generated ideas report higher levels of evaluation than team members converging on crowdsourced ideas.

Besides task-oriented exchanges, team members also perform team-oriented exchanges [36], in which they experience positive and negative emotions through interactions with others [12]. For high-quality social exchanges to emerge, team members should show positive emotions manifested in behaviors that are participative, cooperative, communicative, or forgiving [11]. However, social exchanges may also be characterized with negative emotions [12] that manifest in behaviors such as interactional dominance. An actor that is dominant in interaction asserts control through communication [37]. While past research on social exchange has examined the consequences of emotions $[12,37,38]$, it has not yet been established to what extent the type of exchange resource, in our case self-generated vs. crowdsourced ideas, could be the cause for interactional dominance. We believe that team members converging on self-generated ideas may exert dominance by influencing others with additional information on their self-generated idea. As team members are not aware of the history and background of a crowdsourced idea, they need to base their judgments on their preference and values rather than on informational arguments. This has been referred to as exerting normative influence, which may cause dominant behavior [39]. Dominant behavior might further be facilitated by the absence of the idea contributor during the discussion in a team that is converging on crowdsourced ideas. Related to this, the finding by Davis et al. [40] suggests that voting behavior differs in teams depending on whether the idea's source is anonymous or not. When the idea contributor cannot take part in convergence, team members do not need to be considerate in their communication. However, when teams converge on self-generated ideas, the idea contributor also takes part in the convergence discourse. We anticipate that most team members will try to be respectful and moderate criticism when discussing ideas with the idea 
contributor present not to hurt one's feelings and maintain a positive work environment. Consequently, converging on crowdsourced ideas should be associated with more dominating behavior of individual team members. Thus, we hypothesize

H2: Team members converging on self-generated ideas report less dominant behavior than team members converging on crowdsourced ideas.

Teams without an appointed leader must manage their own activities [10]. This turns the coordination of tasks and responsibilities among team members into another form of social exchange [8]. High social exchange quality manifests when teams perceive their team to be well-coordinated [10]. Past research on social exchange is scarce when it comes to the question of how the exchange resource could affect coordination. One common challenge for teams coordinating themselves is to break down a complex process into activities in order to achieve the team goal [41]. The generation of ideas is typically perceived as easier than clarifying and building support for the promising ideas $[34,42]$. This requires teams to process idea information in-depth, demanding cognitive resources [6]. We argue that teams converging on self-generated ideas have certain advantages over teams that converge on crowdsourced ideas. First, when teams generate ideas online together, they already have a certain level of orientation concerning the kind of generated ideas, as these were visible to everyone throughout the brainstorming process. Visibility of ideas is a characteristic of an idea generation technique that is widely adopted in small internal teams [e.g., 5], but also in crowds [e.g., 43], as generated ideas may function as stimuli to think creatively [44]. Moreover, team members are likely to feel a certain degree of ownership with an idea. In contrast to teams with crowdsourced ideas, they should be faster and more efficient to clarify the meaning of ideas and identify redundancies among ideas. Consequently, teams converging on self-generated ideas should run into fewer coordination problems than teams converging on crowdsourced ideas. Therefore, we hypothesize:

H3: Team members converging on self-generated ideas report better coordination than team members converging on crowdsourced ideas.

A general assumption of social exchange theory is that team members are motivated to interpret feelings of social exchange [45]. When social exchanges are perceived as of high quality, actors experience an emotional uplift [38], which in turn produces global feelings of satisfaction $[10,22]$. Past research further shows that improved integration of information among team members improves their satisfaction [46]. This suggests that increases in the social exchange process of evaluation should be associated with increases in team member satisfaction. Thus, in both cases of teams converging on self-generated and crowdsourced ideas, we hypothesize:

H4: The higher team members' reported level of evaluation, the higher their reported satisfaction with process for teams converging on self-generated ideas ( $\mathrm{H} 4 \mathrm{a}$ ) and on crowdsourced ideas (H4b).

Feelings of satisfaction not only originate from the processing of idea information. A team member may also experience an affective response to another team member, in terms of the team member's behavior in the social exchange process [38]. In this context, dominance represents a specific negative emotion that may cause team members to experience negative feelings towards not only the dominant actor, but also with respect to the process that (s)he is part of. Dominant behavior may lead to team conflicts and lower levels of trust [60], which may negatively impact satisfaction [61]. A number of studies demonstrated a direct negative effect between dominant behavior in traditional and computer-supported teams perceived satisfaction, see e.g. [62, 63]. Thus, dominance is expected to be detrimental to perceived satisfaction, regardless of the source of the brainstormed ideas that teams are working on. Therefore, we hypothesize:

H5: The lower team members' reported dominant behavior, the higher their reported satisfaction with process for teams converging on self-generated ideas (H5a) and on crowdsourced ideas (H5b).

Finally, coordination problems in teams not only negatively impact their social exchanges; they may also have strong negative affective consequences [12]. Coordination problems complicate a team's work process to execute their task. They force teams to expand more cognitive resources on understanding their work, the ideas they are processing, and the procedures that they should follow. This may negatively affect their perceived likelihood of successfully attaining their team goal, which in turn will lead to lower perceived satisfaction, or they may lead teams to feel more frustrated about the process they have to execute $[15,64]$. Thus,

H6: The better team members' reported coordination, the higher their reported satisfaction with process for teams converging on self-generated ideas (H6a) and on crowdsourced ideas (H6b). 


\section{Method \\ 4.1. Subjects}

Participants were recruited from an undergraduate Information Systems course at a European university and randomly assigned to one of two conditions. The condition 'convergence with self-generated ideas' had 64 students in 16 teams. The condition 'convergence with crowdsourced ideas' had 41 students in 11 teams. All participants were randomly assigned into teams of four, with the exception of six teams of three and three teams of five due to no-shows. Students received course credits but no additional compensation. Each team executed the same task.

\subsection{Task}

The task concerns a flooding crisis in a fictitious city called Norvos and was adapted from an existing task [47]. The goal of the task is to come up with help measures that help stabilize the situation in Norvos for the next 7 days. The task represents a decision-making challenge that has no correct answers [48] but has specific convergence goals [29]. While teams in the condition 'convergence with self-generated ideas' had to brainstorm their own ideas, teams in the condition 'convergence with crowdsourced ideas' started their convergence on previously generated help measures. These teams were provided a list of 'crowdsourced' help measures whose number of ideas was adjusted for team size (52 for teams of four students; 39 for teams of three and 65 for teams of five). Students were informed in the task description that those 'crowdsourced' ideas stemmed from a crowdsourcing campaign with city residents. In fact, the ideas were previously generated in a similar lab experiment with students. The lead author selected ideas based on their level of quality, so that each list of 'crowdsourced' ideas had a similar overall quality level. This means that ideas had room for improvement, as some showed limited task-relevance, redundancy, different abstraction levels, or limited development. Both the task description and 'crowdsourced' ideas were presented to a group of bachelor students in their senior year to pre-test them for clarity.

\subsection{Technology}

All teams used the same collaboration technology, ThinkTank v4.9.5 (http://thinktank.net/about) by GroupSystems. Team members could add, edit, reorder, and delete ideas. We trained seven assistants to work with and explain ThinkTank to participants. They also received a short script with instructions to start idea convergence and use ThinkTank. These instructions were consistent across treatments. The assistants did not participate in team discussions; they only answered questions related to ThinkTank.

\subsection{Procedure}

The experiment started with a short warm-up task to familiarize participants with the functionality of ThinkTank. Next, team members read the task description, signed the consent form, and completed the first survey. During that time, assistants in the condition 'convergence with crowdsourced ideas' copied a selection of crowdsourced ideas into ThinkTank depending on team size. In the condition 'convergence with self-generated ideas', teams started brainstorming their own ideas before starting their convergence task. After 50 minutes, the experiment was terminated and participants were instructed to complete the final survey.

\subsection{Measures}

Satisfaction with process. Process satisfaction is the degree to which team members are happy with the way they arrived at their group decision. Items for this construct were adopted from [49].

Social exchange processes. We measured three social exchange processes: evaluation, dominance, and coordination. Evaluation describes the degree to which a team integrates shared information into their decision. We adopted two items from prior research to measure evaluation [50] and developed two additional items to adhere to the suggested minimum threeindicator recommendation [51]. Measures of coordination were adopted from [52]. Coordination describes the degree to which a team processes information effectively and in an orchestrated way. We adopted the instrument to measure dominance from [53]. It describes the degree to which the discussion is dominated by one or a few team members in an unproductive manner.

Work history. Social exchange theory suggests that 'output from a past transaction can be the resource exchanged in a future transaction' [8, p. 889]. Our assignment of subjects to teams was random. Yet, some participants might have worked together in the past, for example on class projects. Therefore, we assessed the extent of work history representing a categorical variable.

\subsection{Analysis procedure}

We used IBM SPSS Statistics 21 to analyze the collected survey data. Initially, we assessed our data for incomplete records on a per-case basis. One of the 
cases needed to be excluded due to incomplete survey data, resulting in 104 remaining cases. We performed univariate and multivariate outlier analysis and deemed all potential outliers satisfactory to retain after investigating them in detail. To remedy missing data, we first checked whether values were missing completely at random (MCAR) before applying the expectation maximization (EM) method to impute missing values. We calculated average scales for the items of each construct and checked them for normality by assessing z-values for skewness and kurtosis. For coordination and evaluation, we applied squared transformations to ensure that the z-values for skewness and kurtosis did not exceed the recommended threshold of $+/-2.58$ at a .01 significance level [51, p. 73]. We assessed the reliability for all measurement constructs with Cronbach's Alpha. We dropped one item with a poor corrected item-total correlation of the construct coordination to meet the minimum recommended Cronbach's Alpha threshold of 0.7 [51]. We examined convergent validity for each construct through exploratory and confirmatory factor analysis. All items loaded on the intended factors. The average variance extracted (AVE) exceeded the minimum recommended threshold of 0.5 [54] for all constructs except for dominance $(\mathrm{AVE}=0.414)$. We retained all items for this construct following Hair's [51] three indicator recommendation. Results of reliability and convergent validity assessments are shown in

Table 1. We further assessed discriminant validity finding both, Fornell and Larcker's [55] criterion as well as the heterotrait-monotrait ratio (HTMT) criterion [56] fulfilled.

Table 1: EFA and CFA - results for all constructs

\begin{tabular}{|c|c|c|c|c|c|c|}
\hline \multirow[b]{2}{*}{ Item Description } & \multirow[b]{2}{*}{ AVE } & \multirow{2}{*}{$\begin{array}{l}\text { Cron- } \\
\text { bach's } \alpha\end{array}$} & \multicolumn{4}{|c|}{ Component } \\
\hline & & & 1 & 2 & 3 & 4 \\
\hline Satisfaction with process & \multirow[t]{6}{*}{0.690} & \multirow[t]{6}{*}{0.878} & & & & \\
\hline The group's problem solving process was efficient. & & & .137 & .753 & .080 & .031 \\
\hline The group's problem solving process was coordinated. & & & .226 & .548 & .226 & .168 \\
\hline The group's problem solving process was fair. & & & -.173 & .945 & -.089 & -.103 \\
\hline The group's problem solving process was understandable. & & & -.031 & .786 & .092 & -.011 \\
\hline The group's problem solving process was satisfying. & & & .070 & .891 & -.148 & .043 \\
\hline Evaluation & \multirow[t]{5}{*}{0.755} & \multirow[t]{5}{*}{0.902} & & & & \\
\hline Out team critically assessed alternatives. & & & .883 & -.026 & -.098 & .043 \\
\hline $\begin{array}{l}\text { Out team considered the viewpoints before making a final } \\
\text { decision. }\end{array}$ & & & .884 & .026 & -.014 & -.080 \\
\hline Our team evaluated ideas thoroughly. & & & .921 & .020 & -.139 & -.073 \\
\hline Our team carefully assessed contributions. & & & .911 & -.020 & .015 & -.100 \\
\hline Dominance & \multirow[t]{4}{*}{0.414} & \multirow[t]{4}{*}{0.755} & & & & \\
\hline $\begin{array}{l}\text { At least one person in my team used up most of the } \\
\text { discussion time without contribution. }\end{array}$ & & & .059 & -.093 & -.344 & .674 \\
\hline $\begin{array}{l}\text { At least one person in my team dominated the discussion } \\
\text { without making relevant comments. }\end{array}$ & & & -.054 & -.048 & .010 & .889 \\
\hline $\begin{array}{l}\text { At least one person in my team participated much more } \\
\text { than other team members. }\end{array}$ & & & -.135 & .101 & .068 & .841 \\
\hline Coordination & \multirow[t]{5}{*}{0.563} & \multirow[t]{5}{*}{0.711} & & & & \\
\hline Our team worked together in a well-coordinated fashion. & & & .426 & -.135 & .642 & .198 \\
\hline $\begin{array}{l}\text { Our team had very few misunderstandings about what to } \\
\text { do. }\end{array}$ & & & -.093 & .036 & .724 & -.036 \\
\hline We accomplished the task efficiently and smoothly. & & & -.013 & .078 & .799 & -.055 \\
\hline $\begin{array}{l}\text { There was much confusion how we would accomplish the } \\
\text { task. (inverse) }\end{array}$ & & & -.156 & -.092 & .803 & -.070 \\
\hline
\end{tabular}

\section{Results}

The descriptive statistics and results of the correlation analysis are depicted in Table 2 and Table 3. We performed an ANOVA to see if teams converging on crowdsourced ideas and teams converging on self- generated ideas differed in terms of the control variable. The results indicate that the two samples do not differ significantly with respect to past working history $(\mathrm{F}(1,102)=1.446, \mathrm{p}>0.05)$. 
Table 2: Descriptive statistics

\begin{tabular}{|l|l|l|}
\hline & $\begin{array}{l}\text { Self-generated } \\
\text { ideas }\end{array}$ & $\begin{array}{l}\text { Crowdsourced } \\
\text { ideas }\end{array}$ \\
\hline & M (SD) & M (SD) \\
\hline $\begin{array}{l}\text { Satisfaction } \\
\text { with process }\end{array}$ & $5.83(0.84)$ & $5.58(0.99)$ \\
\hline Evaluation & $4.74(1.28)$ & $4.65(1.16)$ \\
\hline Dominance & $2.38(1.08)$ & $3.16(1.55)$ \\
\hline Coordination & $5.65(0.81)$ & $5.03(0.80)$ \\
\hline
\end{tabular}

Table 3: Correlations, sg: self-generated, cs: crowdsourced

\begin{tabular}{|l|l|l|l|}
\hline & Satisfaction & Evaluation & Dominance \\
\hline $\begin{array}{l}\text { Satisfaction } \\
\text { with process }\end{array}$ & - & & \\
\hline Evaluation & $\begin{array}{l}\text { sg: } 0.496^{* *} \\
\text { cs:0.536** }\end{array}$ & - & \\
\hline Dominance & $\begin{array}{l}\text { sg: }-0.190 \\
\text { cs:0.115 }\end{array}$ & $\begin{array}{l}\text { sg: }-0.182 \\
\text { cs: } 0.078\end{array}$ & - \\
\hline Coordination & $\begin{array}{l}\text { sg: } 0.669 * * \\
\text { cs: } 0.516^{* *}\end{array}$ & $\begin{array}{l}\text { sg: } 0.426^{* *} \\
\text { cs: } 0.398^{* *}\end{array}$ & $\begin{array}{l}\text { sg: }-0.142 \\
\text { cs:-0.154 }\end{array}$ \\
\hline
\end{tabular}

\subsection{Testing differences in process perceptions}

A multivariate analysis of variance (MANOVA) performed over the set of three dependent variables (evaluation, dominance, coordination) revealed a significant difference between treatments (Pillai's trace $\left.=0.186, \mathrm{~F}(3,100)=7.636, \mathrm{p}=0.000, \eta^{2}=0.186\right)$.

We tested hypotheses 1 through 3 with ANOVA. H1 put forward that teams converging on self-generated ideas would report higher evaluation than teams converging on crowdsourced ideas. Our data did not show any significant differences between the two experimental conditions $(\mathrm{F}(1,102)=0.303, \mathrm{p}>0.05)$. Therefore, $\mathrm{H} 1$ is not supported.

$\mathrm{H} 2$ assumed that dominance should be more prominent in teams with crowdsourced ideas than in teams with self-generated ideas. The Levene's test that assesses the homogeneity of variance between the two samples is significant for dominance. Since the assumption of homogeneity of variance was not met, we performed a Welch's $F$ test [57]. Our results indicate that teams with self-generated ideas show less dominance than teams with crowdsourced ideas (Welch's $F(1,65.064)=7.924, p<0.01)$. Therefore, $\mathrm{H} 2$ is supported.

H3 suggested that teams converging on selfgenerated ideas report higher coordination than their peers converging on crowdsourced ideas. Our analysis supports this and shows that teams with self-generated ideas had better coordination than teams with crowdsourced ideas $(\mathrm{F}(1,102)=15.683, \mathrm{p}<0.01)$ Therefore, $\mathrm{H} 3$ is supported.

\subsection{Testing associations to satisfaction with process}

We applied multiple regression to test hypotheses 4 through 6. We ran regressions separately for teams converging on self-generated ideas (H4a-H6a) and for teams converging on crowdsourced ideas (H4b-H6b). In the first block (control model), we regressed satisfaction with process on the control variable working history for each experimental condition. The coefficient estimate was not significant, neither for teams converging on self-generated ideas $(\beta=0.176$, $p$ $>0.05$ ) nor for teams converging on crowdsourced ideas $(\beta=0.141, p>0.05)$. Both control models explained only little variance of satisfaction with process (adjusted $\mathrm{R}_{\text {self-generated_ideas }}^{2}=0.015$, adjusted $\mathrm{R}_{\text {crowdsourced_ideas }}=-0.005$ ). In the second block (full model), the independent variables were added. Both full models explained a considerable amount of variance (adjusted $\mathrm{R}_{\text {self-generated_ideas }}=0.482$, adjusted $\left.\mathrm{R}_{\text {crowdsourced_ideas }}^{2}=0.391\right)$. The change in $\mathrm{R}^{2}$ was significant in both samples $\left(\mathrm{R}^{2} \Delta_{\text {self- }}\right.$ generated_ideas $=0.485, \mathrm{p}<0.001 ; \quad \mathrm{R}^{2} \Delta_{\text {crowdsourced_ideas }}=$ $0.432, \mathrm{p}<0.001$ ).

Hypothesis 4 suggested that teams with more evaluation report higher satisfaction with process. Evaluation was positively and significantly associated for teams converging on self-generated ideas $(\beta=0.247$, $\mathrm{p}<0.05$ ) as well as teams converging on crowdsourced ideas $(\beta=0.368, p<0.05)$. Therefore, $\mathrm{H} 4 \mathrm{a}$ and $\mathrm{H} 4 \mathrm{~b}$ are supported.

Table 4: Results of hierarchical multiple regression, DV = satisfaction with process

\begin{tabular}{|c|l|l|l|l|}
\hline & \multicolumn{2}{|c|}{ Self-generated ideas } & \multicolumn{2}{c|}{ Crowdsourced ideas } \\
\hline & $\begin{array}{l}\text { Control model } \\
\text { Std. } \beta(\mathrm{t})\end{array}$ & $\begin{array}{l}\text { Full model } \\
\text { Std. } \beta(\mathrm{t})\end{array}$ & $\begin{array}{l}\text { Control model } \\
\text { Std. } \beta(\mathrm{t})\end{array}$ & $\begin{array}{l}\text { Full model } \\
\text { Std. } \beta(\mathrm{t})\end{array}$ \\
\hline Control variable & & & & $0.141(0.890)$ \\
\hline Past working history & $0.176(1.394)$ & $0.100(1.084)$ & $0.188(1.519)$ \\
\hline Independent variables & & & & $0.368(2.701)^{*}$ \\
\hline Evaluation & & $0.247(2.422)^{*}$ & & $0.159(1.255)$ \\
\hline Dominance & & $-0.067(-0.716)$ & & $0.406(2.951)^{*}$ \\
\hline Coordination & & $0.543(5.328)^{* *}$ & & \\
\hline
\end{tabular}




\begin{tabular}{l|l|l|l|l|}
\hline $\mathrm{R}^{2}\left(\right.$ Adjusted $\left.\mathrm{R}^{2}\right)$ & $0.031(0.015)$ & $0.515(0.482)$ & $0.020(-0.005)$ & $0.452(0.391)$ \\
\hline Change in $\mathrm{R}^{2}$ & & $0.485^{* *}$ & & $0.432 * *$ \\
\hline
\end{tabular}
\begin{tabular}{ll}
$* p<0.05, * * p<0.001$ \\
\hline
\end{tabular}

Hypothesis 5 put forward that dominance will be detrimental to satisfaction with process. Our analysis did not find any significant relations $\left(\beta_{\text {self-generated_ideas }}\right.$ $\left.=-0.067, \mathrm{p}>0.05 ; \beta_{\text {crowdsourced_ideas }}=0.159, \mathrm{p}>0.05\right)$. Therefore, H5a and $\mathrm{H} 5 \mathrm{~b}$ are not supported.

Hypothesis 6 suggested that convergence teams with better coordination will report higher satisfaction with the process. Coordination was positively related to satisfaction with process in teams converging on selfgenerated ideas $(\beta=0.543, \mathrm{p}<0.001)$ as well as teams converging on crowdsourced ideas $(\beta=0.406, p<0.05)$. Therefore, H6a and H6b are supported.

\section{Discussion and Conclusions}

The goal of this study was to investigate a number of specific social exchange processes (evaluation, dominance, and coordination) during a convergence process in teams that are either working with selfgenerated or crowdsourced ideas. The results demonstrate that teams with self-generated ideas reported higher coordination and less dominant behavior. Also, higher levels of perceived evaluation and coordination are associated with higher perceived process satisfaction for both teams working on selfgenerated and crowdsourced ideas.

Our findings contradict past research that argued: 'it does not matter if a group diverges before they converge. In other words, it is not necessary for a group to brainstorm the ideas that they will be refining and clarifying during the convergence activity' $[28, \mathrm{p}$. 214]. Our findings show that evaluation and coordination affect satisfaction for both self-generated and crowd-generated settings. Since teams working with crowdsourced ideas reported lower coordination, the role of process structure might become even more crucial for idea convergence in crowdsourcing situations. The implication of this finding is that facilitation techniques focusing on process structuring - which have been developed and tested in small group research - should be explored in the context of idea convergence with crowdsourced ideas. Recent research on human facilitation shows promising results of how specific convergence interventions could be used for improved convergence quality, shared understanding, and satisfaction $[58,59]$.

Our findings further suggest that dominance does not appear to affect satisfaction with process. This is encouraging in the context of crowdsourcing situations, where dominance is more likely, according to our findings. Yet, dominance as a social exchange process might be important for other important outcomes, such as shared understanding, team cohesion, and perceived self-efficacy.

A number of limitations have to be considered when interpreting the results of this study. First, our study investigated social exchange processes in a face-toface setting. Future research will explore social exchange processes during idea generation and convergence activities in distributed configurations to determine whether similar results will be found. Second, we measured the three social exchange processes through self-reports (survey). Perceptions of one's own and others' behaviors may not accurately reflect observable behaviors. Therefore, we plan to use methods such as discourse analysis, coding of video recordings and technology transcripts with a deductively informed coding schema to determine whether the results are consistent. Third, we did not consider potential interaction effects in this analysis. For example, the degree of perceived conflict or engagement could play a moderating role.

\section{Acknowledgements}

The research leading to the presented results was partially funded by the Austrian Science Foundation (Erwin-Schrödinger Scholarship of the FWF Project Nr. J3735-G27)

\section{References}

[1] T. Economist. (2016, June 9). Europe's migrant crisis in numbers. Available: http://www.economist.com/blogs/graphicdetail/2016/0 3/daily-chart-20

[2] W. Zhang and Q. Zhang, "Multi-stage evaluation and selection in the formation process of complex creative solution," Quality \& Quantity, vol. 48 (5), 2014, pp. 2375-2404.

[3] T. E. Drabek and D. A. McEntire, "Emergent phenomena and the sociology of disaster: lessons, trends and opportunities from the research literature," Disaster Prevention and Management: An International Journal, vol. 12 (2), 2003, pp. 97-112.

[4] A. Majchrzak, S. L. Jarvenpaa, and A. B. Hollingshead, "Coordinating expertise among emergent groups responding to disasters," Organization Science, vol. 18 (1), 2007, pp. 147-161.

[5] K. Girotra, C. Terwiesch, and K. T. Ulrich, "Idea generation and the quality of the best idea," Management Science, vol. 56 (4), 2010, pp. 591-605.

[6] E. F. Rietzschel, B. A. Nijstad, and W. Stroebe, "The selection of creative ideas after individual idea generation: Choosing between creativity and impact," 
British Journal of Psychology, vol. 101 (1), 2010, pp. 47-68.

[7] R. O. Briggs, G. J. De Vreede, and J. F. Nunamaker, "Collaboration engineering with ThinkLets to pursue sustained success with group support systems," Journal of Management Information Systems, vol. 19 (4), 2003, pp. 31-64.

[8] R. Cropanzano and M. S. Mitchell, "Social exchange theory: An interdisciplinary review," Journal of management, vol. 31 (6), 2005, pp. 874-900.

[9] J. E. Mathieu, T. S. Heffner, G. F. Goodwin, E. Salas, and J. A. Cannon-Bowers, "The influence of shared mental models on team process and performance," Journal of Applied Psychology, vol. 85 (2), 2000, pp. 273-283.

[10] A. Seers, "Team-member exchange quality: A new construct for role-making research," Organizational Behavior and Human Decision Processes, vol. 43 (1), 1989, pp. 118-135.

[11] M. S. Cole, W. S. Schaninger, and S. G. Harris, "The workplace social exchange network a multilevel, conceptual examination," Group \& Organization Management, vol. 27 (1), 2002, pp. 142-167.

[12] E. J. Lawler, "An affect theory of social exchange," American Journal of Sociology, vol. 107 (2), 2001, pp. 321-352.

[13] R. C. Liden, R. T. Sparrowe, and S. J. Wayne, "Leader-member exchange theory: The past and potential for the future," Research in personnel and human resources management, 15, 1997, pp. 47-120.

[14] H. Liao, D. Liu, and R. Loi, "Looking at both sides of the social exchange coin: A social cognitive perspective on the joint effects of relationship quality and differentiation on creativity," Academy of Management Journal, 53 (5), 2010, pp. 1090-1109.

[15] R. O. Briggs, B. A. Reinig, and G. J. de Vreede, "The Yield Shift Theory of Satisfaction and Its Application to the IS/IT Domain," Journal of the Association for Information Systems, vol. 9 (5), 2008, pp. 267-293.

[16] S. Petter, W. DeLone, and E. R. McLean, "Information Systems Success: the quest for the independent variables," Journal of Management Information Systems, vol. 29 (4), 2013, pp. 7-62.

[17] A. Bhattacherjee, "Understanding information systems continuance: an expectation-confirmation model," MIS Quarterly, vol. 25 (3), 2001, pp. 351-370.

[18] P. M. Blau, Exchange and power in social life: Transaction Publishers, 1964.

[19] R. M. Emerson, "Social exchange theory," Annual review of sociology, 1976, pp. 335-362.

[20] C. C. Schermuly and B. Meyer, "Good relationships at work: The effects of Leader-Member Exchange and Team-Member Exchange on psychological empowerment, emotional exhaustion, and depression," Journal of Organizational Behavior, vol. online, 2015.

[21] J. Jin, Y. Li, X. Zhong, and L. Zhai, "Why users contribute knowledge to online communities: An empirical study of an online social Q\&A community," Information \& Management, vol. 52 (7), 2015, pp. 840-849.
[22] G. C. Banks, J. H. Batchelor, A. Seers, E. H. O'Boyle, J. M. Pollack, and K. Gower, "What does teammember exchange bring to the party? A meta-analytic review of team and leader social exchange," Journal of Organizational Behavior, vol. 35 (2), 2014, pp. 273295.

[23] L. D. Molm, "Theoretical comparisons of forms of exchange," Sociological Theory, 21 (1), 2003, 1-17.

[24] M. A. Marks, J. E. Mathieu, and S. J. Zaccaro, "A Temporally Based Framework and Taxonomy of Team Processes," The Academy of Management Review, vol. 26 (3), 2001, pp. 356-376.

[25] J. Mathieu, M. T. Maynard, T. Rapp, and L. Gilson, "Team Effectiveness 1997-2007: A Review of Recent Advancements and a Glimpse Into the Future," Journal of Management, vol. 34 (3), 2008, pp. 410-476.

[26] G. J. De Vreede, R. O. Briggs, and A. P. Massey, "Collaboration engineering: Foundations and opportunities: Editorial to the special issue on the journal of the association of information systems," Journal of the Association for Information Systems, vol. 10 (3), 2009, pp. 121-137.

[27] K. Fu, J. Cagan, and K. Kotovsky, "Design team convergence: The influence of example solution quality," Journal of Mechanical Design, vol. 132 (11), 2010, pp. 1-11.

[28] A. Davis, V. Badura, G. J. de Vreede, and A. S. Read, "Understanding Methodological Differences to Study Convergence in Group Support System Sessions," in Groupware: Design, Implementation, and Use, R. O. Briggs, P. Antunes, and G.-J. de Vreede, Eds., ed Berlin-Heidelberg: Springer, 2008, pp. 204-216.

[29] A. Davis, G. J. de Vreede, and R. O. Briggs, "Designing thinkLets for convergence," presented at the AMCIS 2007 Proceedings, Paper 358, 2007.

[30] H. Chen, P. Hsu, R. Orwig, L. Hoopes, and J. F. Nunamaker, "Automatic concept classification of text from electronic meetings," Communications of the ACM, vol. 37 (10), 1994, pp. 56-73.

[31] G. L. Kolfschoten and F. M. Brazier, "Cognitive Load in Collaboration: Convergence," Group Decision and Negotiation, vol. 22 (5), 2013, pp. 975-996.

[32] M. den Hengst and M. Adkins, "Which collaboration patterns are most challenging: A global survey of facilitators," in Proceedings of the 40th Annual Hawaii International Conference on System Sciences, Los Alamitos, CE, 2007, pp. 248-257.

[33] N. W. Kohn, P. B. Paulus, and Y. Choi, "Building on the ideas of others: An examination of the idea combination process," Journal of Experimental Social Psychology, vol. 47 (3), 2011, pp. 554-561.

[34] P. B. Paulus and V. R. Brown, "Toward more creative and innovative group idea generation: a cognitivesocial-motivational perspective of brainstorming," Social and Personality Psychology Compass, vol. 1 (1), 2007, pp. 248-265.

[35] M. Ross and F. Sicoly, "Egocentric biases in availability and attribution," Journal of personality and social psychology, vol. 37 (3), 1979, p. 322.

[36] H. H. M. Tse and M. T. Dasborough, "A Study of Exchange and Emotions in Team Member 
Relationships," Group \& Organization Management, vol. 33 (2), 2008, pp. 194-215.

[37] N. E. Dunbar, A. M. Bippus, and S. L. Young, "Interpersonal dominance in relational conflict: A view from dyadic power theory," Interpersona, vol. 2 (1), 2008, p. 1.

[38] E. J. Lawler and S. R. Thye, "Bringing emotions into social exchange theory," Annual review of sociology, 1999, pp. 217-244.

[39] W. W. Huang and K.-K. Wei, "An empirical investigation of the effects of group support systems (GSS) and task type on group interactions from an influence perspective," Journal of Management Information Systems, vol. 17 (2), 2000, pp. 181-206.

[40] J. Davis, M. Zaner, S. Farnham, C. Marcjan, and B. P. McCarthy, "Wireless brainstorming: Overcoming status effects in small group decisions," in System Sciences, 2003. Proceedings of the 36th Annual Hawaii International Conference on, 2003, p. 10 pp.

[41] B. C. Wheeler and J. S. Valacich, "Facilitation, GSS, and training as sources of process restrictiveness and guidance for structured group decision making: An empirical assessment," Information Systems Research, vol. 7 (4), 1996, pp. 429-450.

[42] O. M. Bjelland and R. C. Wood, "An inside view of IBM's' Innovation Jam'," MIT Sloan management review, vol. 50 (1), 2008, p. 32.

[43] A. Armisen and A. Majchrzak, "Tapping the innovative business potential of innovation contests," Business Horizons, vol. 58 (4), 2015, pp. 389-399.

[44] A. Pinsonneault, H. Barki, R. B. Gallupe, and N. Hoppen, "Electronic brainstorming: The illusion of productivity," Information Systems Research, vol. 10 (2), 1999, pp. 110-133.

[45] E. E. Lawler, S. A. Mohrman, and G. E. Ledford, Creating high performance organizations: Practices and results of employee involvement and total quality management in Fortune 1000 companies: Jossey-Bass San Francisco, 1995.

[46] K. McNamara, A. R. Dennis, and T. A. Carte, "It's the thought that counts: The mediating effects of information processing in virtual team decision making," Information Systems Management, vol. 25 (1), 2008, pp. 20-32.

[47] E. L. Santanen, R. O. Briggs, and G. J. De Vreede, "Causal Relationships in Creative Problem Solving: Comparing Facilitation Interventions for Ideation," Journal of Management Information Systems, vol. 20 (4), 2004, pp. 167-197.

[48] J. E. McGrath, Groups: Interaction and Performance. New Jersey: Prentice-Hall, Inc., 1984.

[49] B. A. Reinig, "Toward an Understanding of Satisfaction with the Process and Outcomes of Teamwork," Journal of Management Information Systems, vol. 19 (4), 2003, pp. 65-84.

[50] M. Limayem and G. DeSanctis, "Providing Decisional Guidance for Multicriteria Decision Making in Groups," Information Systems Research, vol. 11 (4), 2000, pp. 386-401.

[51] J. F. J. Hair, W. C. Black, B. J. Babin, and R. E. Anderson, Multivariate data analysis: A global perspective vol. 7th edition. New Jersey: Pearson Education, 2010.

[52] K. Lewis, "Measuring transactive memory systems in the field: scale development and validation," Journal of Applied Psychology, vol. 88 (4), 2003, pp. 587-604.

[53] R. C.-W. Kwok, J. Ma, and D. R. Vogel, "Effects of group support systems and content facilitation on knowledge acquisition," Journal of Management Information Systems, vol. 19 (3), 2003, pp. 185-230.

[54] J. F. Hair Jr, G. T. M. Hult, C. Ringle, and M. Sarstedt, A primer on partial least squares structural equation modeling (PLS-SEM): Sage Publications, 2013.

[55] C. Fornell and D. F. Larcker, "Evaluating structural equation models with unobservable variables and measurement error," Journal of marketing research, 1981, pp. 39-50.

[56] J. Henseler, C. M. Ringle, and M. Sarstedt, "A new criterion for assessing discriminant validity in variance-based structural equation modeling," Journal of the Academy of Marketing Science, vol. 43 (1), 2015, pp. 115-135.

[57] D. Howell, Statistical methods for psychology, 8th ed. Belmont, CA: Wadsworth Cengage Learning, 2012.

[58] I. Seeber, R. Maier, B. Weber, G. J. De Vreede, T. De Vreede, and A. Alothaim, "Brainstorming Is Just the Beginning: Effects of Convergence Techniques on Satisfaction, Shared Understanding, and Perceived Usefulness of Moderation in Teams," in 48th Hawaii International Conference on System Science (HICSS) Hawaii, 2015, pp. 581-590.

[59] I. Seeber, R. Maier, G. J. De Vreede, B. Weber, and A. Merz, "Exploring Idea Quality Evolution During Convergence," presented at the International Conference on Information Systems, Fort Worth, Texas, 2015.

[60] Watson-Manheim, M.B. and Belanger, F. Support for communication-based work processes in virtual work. e-Service Journal (2002).

[61] Montoya-Weiss, M. M., Massey, A. P., \& Song, M. (2001). Getting it together: Temporal coordination and conflict management in global virtual teams. Academy of Management Journal, 44(6), 1251-1262.

[62] Schoenecker, T.S., K.D. Martell, \& J. F. Michlitsch. "Diversity, performance, and satisfaction in student group projects: An empirical study." Research in Higher Education 38.4 (1997): 479-495.

[63] Mejias, Roberto J. "The interaction of process losses, process gains, and meeting satisfaction within technology-supported environments." Small Group Research 38.1 (2007): 156-194.

[64] Piccoli, Gabriele, Anne Powell, and Blake Ives. "Virtual teams: team control structure, work processes, and team effectiveness." Information Technology \& People 17.4 (2004): 359-379. 